\title{
Actitudes lingüísticas de los nativos hablantes de quechua hacia los hablantes de aimara
}

\section{Linguistic Attitudes From Quechua-Speaking Natives Towards Aymara Speakers}

\author{
Adán Ochoa Yupanqui \\ Universidad Nacional Mayor de San Marcos, Lima, Perú \\ adan.ochoay@gmail.com
}

\begin{abstract}
Resumen
En este artículo se pretende descubrir las actitudes de los quechua hablantes nativos hacia el aimara. Es un estudio de tipo cualitativo, la muestra es no-probabilística y está compuesta por cinco colaboradores hablantes nativos de quechua que actualmente viven en Lima y migraron desde jóvenes a dicha ciudad. Dos de estos colaboradores proceden de dos localidades de Puno, otros dos provienen de localidades de Cusco y una, de Apurímac. Sus edades varían entre los 52 y 76 años. Se procedió a aplicar una entrevista semiestructurada con preguntas directas e indirectas para descubrir sus actitudes lingüísticas hacia el aimara en sus diversos componentes. El artículo concluye que los quechua hablantes tienden a presentar actitudes lingüísticas variantes entre neutras y negativas hacia el aimara en el componente afectivo y una clara actitud negativa en el componente cognoscitivo, debido a las oportunidades laborales y el prestigio del aimara a nivel nacional.
\end{abstract}

Palabras claves: actitudes lingüísticas frente al aimara, justicia sociolingüística, ideologías lingüísticas.

\begin{abstract}
The main purpose of this study is to show the attitudes from Quechua native speakers towards Aymara native speakers. This survey is cualitative, its sample is non-probabilistic, and it is composed by five people Quechua native speakers who live in Lima and arrived to this city since they were young. Two of them were born in two localities of Puno, other two people come from localities of Cusco and the remaining one comes from Apurimac. Their ages are from 52 to 76 years old. The data collection was made by a semi structured interview composed by direct and indirect questions to find out their linguistic attitudes towards the aymara language and their users in several aspects. In this article I conclude that Quechua speakers tend to show linguistic attitudes which vary among neutral and negative ones regarding to the cognitive component, because of job opportunities and the prestige of Aymara language at the national level.
\end{abstract}

Keywords: linguistic attitudes, linguistic attitudes towards Aymara, sociolinguistic justice, linguistic ideologies. 
Actitudes lingüísticas de los nativos hablantes de quechua hacia los hablantes de aimara Adán Ochoa Yupanqui

\section{Introducción}

En el contexto peruano, territorio en el que conviven numerosas lenguas, las que tienen mayor importancia en términos de cantidad de hablantes son dos lenguas andinas, i.e., el quechua y el aimara. Las investigaciones realizadas en relación a actitudes lingüísticas hasta el momento han sido frecuentemente orientadas desde el mundo hispanohablante hacia alguna de las lenguas originarias. El presente artículo está referido a la lengua aimara y tiene por objetivo indagar acerca de las actitudes lingüísticas por parte de los hablantes nativos de quechua de diversas variedades, tanto en los componentes afectivos como en los componentes cognitivos.

Esta investigación es de tipo cualitativo, por lo que sus resultados no son generalizables, y también es exploratoria y pionera, en el sentido de que no existen antecedentes directos sobre las actitudes de quechua hablantes frente al aimara, aunque sí existen estudios de actitudes desde otras lenguas, como Hentschel (2016), Jimenez (2017). Por último, esta investigación, como muchas otras, tiene la finalidad de que se conozca y actualice la información disponible acerca de la importancia que tiene la revitalización lingüística, la cual pasa por la mejora en la valoración y se puedan tomar medidas que optimicen los resultados gracias a una mejor identificación de los problemas para una aplicación de políticas lingüísticas que respondan a la realidad y que evite generar divisiones entre las diversas lenguas originarias.

Las lenguas originarias en el Perú están siendo estudiadas cada vez con mayor frecuencia en diversos aspectos, sean estos estructurales (fonológicos, morfosintácticos o semánticos) o desde perspectivas sociolingüísticas, dada su situación de contacto lingüístico con otras, así como con el castellano (Cerrón-Palomino, 1987; Merma, 2007).

El presente artículo contiene un marco teórico en el que se deja clara la base científica del mismo y a partir del cual se elaborarán los conceptos, sus relaciones y el análisis que estos permitirán realizar; luego, también contiene un apartado para la metodología, el cual contiene el alcance del artículo, el tipo de investigación, el momento de aplicación, la población, la muestra y las técnicas e instrumentos. La sección siguiente a la metodología contiene el análisis y finalmente se presentan las conclusiones que se obtienen. 


\section{Marco teórico}

En este apartado, se precisa lo que son las actitudes en general, esto es, desde la psicología social, y específicamente lo que son las actitudes lingüísticas.

\subsection{Actitudes}

Las actitudes son un concepto abordado principalmente por la psicología social y enmarcada en la teoría del mismo nombre. Está orientada a las reacciones de diversa naturaleza que pueden tener las personas ante objetos diversos. Estas reacciones pueden considerarse como aquellas visibles o como las que están subyacentemente en la mente de los individuos. En el primer caso, se ubica en la teoría conductista y, en el segundo caso, en la teoría mentalista de las actitudes. Las reacciones mencionadas pueden estar motivadas por una predisposición neurológica que, a su vez, es la síntesis de sus dotaciones genéticas y el desarrollo epigenético o cultural que ha tenido el individuo. Por lo tanto, tanto las experiencias como las creencias son factores que influyen en las actitudes (Falcón y Mamani, 2017).

Siguiendo a Kierig (2016), Vizcarra (2012), Jimenez (2017) y Cuba (2018), las actitudes tienen tres componentes: un componente cognoscitivo, un componente afectivo y un componente conductual. El primero de ellos se refiere a lo que uno racionaliza acerca del objeto, el componente afectivo consiste en las reacciones emotivas que provoca el objeto y, por último, el componente conductual está referido a cómo se manifiesta en el comportamiento las actitudes que tenemos frente a los objetos.

Además, según Vizcarra (2012), toda actitud tiene cuatro características: i) dirección, que puede ser positiva o negativa; ii) magnitud, la cual refleja el sentido en que es positiva o negativa una actitud; iii) intensidad, la cual implica la fuerza con que se asocia la actitud, y iv) saliencia o centralidad, que es la relevancia que el individuo le da inconscientemente a la actitud de manera que determinará su conducta.

\subsection{Actitudes lingüísticas}

La actitud lingüística, de acuerdo con Kierig (2016), es una forma de evidenciarse la actitud social de los individuos que se caracteriza por referirse a la lengua, pero también a su uso y sus variedades. 
Actitudes lingüísticas de los nativos hablantes de quechua hacia los hablantes de aimara Adán Ochoa Yupanqui

Las actitudes lingüísticas, como las actitudes en general, son aprendidas, por lo que está extendido en toda la población y están presentes en las actividades cotidianas de los individuos.

Por otra parte, las actitudes lingüísticas son indicadores de las valoraciones que hacen los individuos a una comunidad lingüística determinada.

Kierig (2016), además, señala que, en una situación de contacto lingüístico, la selección de una lengua u otra en su comunicación es un indicador de la actitud que tiene hacia dichas lenguas.

Asimismo, las actitudes mostradas hacia los diversos grupos sociales, se traducen en una reacción ante la indexación que resulta a partir de ciertos rasgos presentes en la lengua y se plasman finalmente en los propios hablantes.

Por otra parte, como en todas las actitudes, las actitudes lingüísticas también pueden ser estudiadas desde las perspectivas conductiva y mentalista. La primera toma directamente el comportamiento como la actitud de la persona. Esto involucra el uso real de la lengua en diversos contextos. No obstante, esta perspectiva no permite hacer predicciones, a diferencia de la perspectiva mentalista, la cual realiza inferencias a partir de los comportamientos para llegar a las actitudes como estados mentales (Jimenez, 2017).

De acuerdo con Sihua (2015), la perspectiva mentalista requiere de técnicas que efectivamente den cuenta de las actitudes como predisposiciones subyacentes a los comportamientos. Estas técnicas suelen incluir métodos directos y entrevistas con preguntas acerca de situaciones hipotéticas, sin embargo, estas pueden tener algunos sesgos debido a que el entrevistado puede estar incentivado a responder conforme a lo que piensa que será bien recibido por el entrevistador.

Esta investigación está enmarcada en la consideración de las actitudes como una práctica discursiva, como lo denomina la misma autora, en la cual se detectan las estrategias y marcas discursivas que utilizan los individuos para comunicarse y para referirse a una lengua determinada.

Por otra parte, según Vizcarra (2012), como toda actitud, las actitudes lingüísticas pueden ser de aceptación o rechazo, esto se puede expresar como lealtad a la lengua o aversión a la lengua. Sus causas pueden ubicarse en el orden neurológico o social, pero sea cual fuere su última causa, la actitud es una predisposición o tendencia adquirida por el entorno o experiencias personales asociadas a la lengua en cuestión. 


\section{Metodología}

Esta investigación es exploratoria y cualitativa, sus resultados no son generalizables, pues no se utilizan técnicas estadísticas, aunque sí es posible realizar una de este tipo con los recursos suficientes. Además, esta investigación es exploratoria y no hay acceso libre a antecedentes directos de los cuales se pueda hacer una réplica. La población seleccionada para el análisis está conformada por los hablantes nativos de quechua (quechua IIC de Ayacucho y Cuzco-Collao, tanto de Cuzco como de Puno) de distintas variedades o procedencias. En consecuencia, la muestra está conformada por personas que cumplen con estas características. Además, cabe mencionar que la muestra fue no-probabilística y las personas fueron seleccionadas mediante el criterio de la accesibilidad. Estas son: Luis Dionisio Ytusaca Parqui, de 63 años de edad, proveniente de proveniente de Puno, llegó a Lima a los 14 años aproximadamente; Adelaida Quispe Gamarra, de 61 años de edad y proveniente de la hacienda de Tarocane, distrito Putina, Azángaro, Puno; Victoria Altamirano Huamán, de 76 años de edad y Justina Celia Quispetupa Corimaña, de 64 años de edad, provenientes de San Jerónimo, Cusco; y Lucía Gutiérrez Salcedo, 52 años, proveniente de Andahuaylas, Anexo Huaccana, Apurímac, y llegó a Lima a los 13 años de edad.

A cada uno de ellos se le aplicó una entrevista semidirigida que contiene preguntas para averiguar sus datos personales, perfil, procedencia y también contiene preguntas directas e indirectas para poder capturar las actitudes lingüísticas en sus facetas afectivas y cognoscitivas. Las actitudes que se han capturado son tanto hacia su propia lengua, esto es, el quechua; hacia el aimara, y hacia el castellano. Esto debido a que en una misma respuesta o en respuestas consecutivas que se relacionen muy estrechamente se pueden realizar comparaciones entre las marcas discursiva o estrategias que utiliza el colaborador para hacer eficiente su comunicación. Sería muy complicado o poco riguroso realizar estas comparaciones de marcas discursivas en respuestas a distintas preguntas o en contextos alejados, tanto temporalmente como temáticamente. Las actitudes conductuales no son verificables en nuestra investigación, dado que se necesitaría de otras técnicas que permitan la observación espontánea de los colaboradores.

Las entrevistas se realizaron con una grabadora TASCAM modelo DR-05 durante el mes de setiembre de 2019. 
Actitudes lingüísticas de los nativos hablantes de quechua hacia los hablantes de aimara Adán Ochoa Yupanqui

\section{Análisis}

A continuación, se presenta el análisis de los datos obtenidos por el registro realizado con la grabadora TASCAM DR-05. Cada colaborador tiene una subsección en este acápite y se presentan de manera ordenada los datos personales y los datos más relevantes capturados en la entrevista. En los fragmentos que incluyen el diálogo tanto del entrevistador como del entrevistado, se codificará con $P$ y $R$, respectivamente.

\subsection{Adelaida Quispe}

Adelaida Quispe llegó a Lima entre sus 16 o 17 años.

A la pregunta 4, Adelaida contesta asignando el calificativo de brusco a las lenguas quechua y también al aimara. Se observa en el extracto a continuación lo correspondiente a la primera.

R: El quechua es difícil para los que no hablan por las letras que llevan, por la forma de las letras suena brusco. Esas palabritas son un poco bruscas para los que hablan castellano y no lo pueden escribir tampoco correctamente, no?

$P:$ ¿Y el castellano, es difícil hablar el castellano?

$R$ : No, eso es más fácil, porque no acompaña con otras cosas, pe, porque es más fácil.

$P:$ ¿Por qué es más fácil hablar el castellano?

$R:$ No, porque uno va aprendiendo a leer eh::: vas conociendo el castellano, no? $Y$ entonces, más fácil que quechua, porque no acompaña con otras letras: (o.4) fuertes, pues, o sea que es corrido, se puede hablar más fácil. Porque primera vez cuando uno es quechuahablante eso que está difícil, que moteas, pero una vez que hablas es perfectamente para escribir más fácil.

Se está haciendo referencia a las grafías y diacríticos utilizados en la escritura del aimara y también a los del quechua, tales como las que representan a los sonidos fricativo glotal y oclusivo glotal, los cuales no tienen un correspondiente en el castellano y se hace necesaria la adición de un sonido a una letra que no lo tiene, en castellano, y la inserción de la comilla simple para designar el fono oclusivo glotal.

Esto le lleva a concluir que el quechua es brusco, adjetivo cargado de una connotación negativa. También utiliza el adjetivo fuerte, que va acorde al anterior

34 Lengua \& Sociedad. Revista de Lingüística Teórica y Aplicada 
adjetivo e implica que hay mucha energía destinada a hablar para aquella persona que utiliza el quechua. Asimismo, estos adjetivos connotan una reacción no-razonada, por lo que constituye el componente conductual de las actitudes.

En el siguiente fragmento, se observa que la percepción de la entrevistada es que el quechua es más fácil de hablar, dado que es competente en esa lengua, pero le añade la acotación de que, desde un punto de vista objetivo, el castellano es inherentemente más fácil de aprender, sea como oyente o en su escritura.

P: ¿Cuál es más fácil hablar quechua o castellano?

R: Más fácil para mí, como yo he nacido en quechua, es quechua, pues, claro [...] Pero yo califico para los que vienen de otro país, así, es castellano más rápido para entender, escribir.

Posteriormente, en cuanto se le interroga sobre la dificultad de hablar en aimara, expresa que también es brusco y es comparable con el quechua en este aspecto, además, nuevamente hace referencia al esfuerzo físico para la articulación de los sonidos.

\section{$P:$ ¿Será difícil hablar aimara?}

R: Sí, es difícil, es brusco [...] Por ahí van, quechua y castellano van por ahí, mejor dicho, quechua y aimara van casi por ahí. Yo tampoco no sé tan, hablar un dejo también se jala distinto para poder sonar la letra, no?

$P$ : Los sonidos...

$R$ : Ah, los sonidos de la lengua.

Cuando se le pregunta sobre el gusto de hablar en quechua, responde que sí le gusta y que ese gusto se justifica en que es la lengua que ha adquirido durante su primera infancia. Asimismo, se puede notar que concibe la existencia de formas correctas e incorrectas en el quechua, aunque no se precisa cuál es porque no se relaciona a una variedad concreta, solamente señala que entre los mismos hablantes de quechua se corrigen.

$P:$ ¿Te gusta hablar en quechua?

R: Sí.

$P:$ ¿Por qué?

$R$ : Porque yo no quiero hablar o yo no quiero olvidarme mi idioma natal, porque he nacido con ese idioma, es muy gusto para hablar. Es para mí sagrado hablar 
Actitudes lingüísticas de los nativos hablantes de quechua hacia los hablantes de aimara Adán Ochoa Yupanqui

con quien me encuentro con las quechuistas hablamos bie:n, con ayacuchano, con cusqueño, apurimeño. Hablamos bien, claro, hay variedad, un poquito varían palabras, pero sí nos entendemos bien. Entre nosotros nos corregimos.

También, considera que el quechua es más sentimental que el castellano, como parte del componente afectivo; pero no puede compararlo con el aimara, debido a que no es competente en esa lengua.

$P:$ ¿Cuál es más sentimental?

$R$ : Quechua [...] es bien sentimiento, pero como no sé hablar aimara, no sé será también.

$P:$ ¿Y el castellano qué tal es? ¿Más seco?

$R$ : No, normal es, es, ya muy popular, pues, para todos que hablan, todo el mundo, aprenden, en cambio quechua es propio, pues.

Hay que notar que no dice explícitamente que el castellano tenga menor capacidad para ser sentimental, sino que lo califica como normal por su frecuencia de uso e implícitamente por su carácter sentimental. También, implícitamente, expresa que el quechua es más sentimental por el hecho de que es propio, a diferencia del castellano que le es ajeno en alguna medida.

En cuanto al prestigio, como parte del componente cognitivo de las actitudes lingüísticas, ella considera que el quechua, actualmente, sí lo tiene, dadas las condiciones económicas que lo promueven debido al turismo. A diferencia del pasado, en el que no solo carecía de prestigio, sino que incluso era mal visto hablar en quechua.

$P: ¿ E l$ quechua tiene prestigio a nivel nacional?

R: Sí.

P: ¿Por qué?

R: Porque ahora como ya llegan los turistas de otros países, entonces llegan a provincias, por ejemplo ahí está Machu Picchu, todo, no? Es que ahí s: hablan quechua neto, entonces más comunicación hay, pues. Más es para conversar con la gente que están a los rincones, entonces más necesario es hablar.

$P:$ Ah ya, por la necesidad...

$R$ : Porque los turistas quieren hablar y no lo comprenden. Es necesario aprender más quechua.

36 Lengua \& Sociedad. Revista de Lingüistica Teórica y Aplicada 
$P:$ ¿Y antes tendría prestigio el quechua?

R: No, no, porque era un poco::: cómo se puede decir mmm...

P: Discriminado?

$R$ : No, no era criminado, un poco nos temíamos que::: no era tan este visto quechua hablar, nos decían serranos, así, entonces, no tanto soltábamos hablar quechua con así, siempre teníamos que contestar a la gente con castellano, así venían y más también eran antes la gente muy machistas, se podría decir. Ahora no, el que menos quieren aprender algo en quechua, hasta en los colegios están exigiendo quechua. [...] Antes no tanto, era un poco criminación, también se diría, no?

P: Ahh ya, ahora, como que ha cambiado, no?

$R$ : Ha cambiado y más la gente ahora quieren aprender quechua.

Es conveniente resaltar que cae en ligera contradicción o, en todo caso, se rectifica en cuanto al hecho de que el quechua era discriminado llegando a la conclusión de que sí lo era.

Cuando se pasa a formular la misma pregunta en el caso del aimara, la respuesta es claramente distinta, pues, a pesar de encontrarse geográficamente muy cerca o, incluso, superpuestas las comunidades lingüísticas quechua y aimara, esta no parece ser promovida implícitamente por el turismo, como sí sucede con el quechua, por lo que su valoración es menor.

P: Y en el caso del aimara, ¿el aimara tendrá prestigio a nivel nacional?

$R$ : No tanto, no he escuchado, no, no te podría decir mucho de ese caso. No tanto, sí, algunos seguro que llegan a aprender, no, más es el quechua he escuchado donde van siempre están en queriendo hablar quechua y por los gringos también cuando uno habla en plaza de armas, por ahí cuando vamos estamos hablando, se acercan y el problema es que tampoco entendemos tampoco su idioma, qué nos estará hablando.

P: Y el castellano, ¿tendrá prestigio a nivel nacional?

$R$ : Claro, pues, si:::hh donde vas, la gente sabe castellano, pues, fácil te puedes comunicar. Castellano es ya general ya pues. Donde llegas a esos quién no habla castellano. Donde llegas ya con castellano puedes comunicarte con la gente.

El castellano es la lengua que cuenta con mayor prestigio y la más utilizada, evidentemente, de acuerdo con Adelaida.

Cuando se le pregunta sobre su interés en aprender aimara, se muestra bastante interesada, aunque reconoce las limitaciones prácticas. 
Actitudes lingüísticas de los nativos hablantes de quechua hacia los hablantes de aimara Adán Ochoa Yupanqui

R: Me gustaría, yo siempre he soñado aprender aimara, pero no tengo este: posibilidad de aprender. Quiero aprender, sino que es un poquito difícil, te olvidas. Yo me olvido, pa mí hablan, sí, pero no sé qué me estarán hablando, pues.

Para la organización de eventos, se ve una preferencia por una persona hispanohablante monolingüe.

$R$ : Es para que organice las actividades del barrio. Por ejemplo acá que hagan, no sé, el aniversario de Mariátegui.

$P:$ No, pues, con la persona que habla castellano, nomás, pues, ni modo quechua, no? Porque poco hablan.

Además, después explica que incluso es mejor que organice las actividades un quechuahablante que un aimarahablante.

Cuando se le pregunta sobre qué lengua constituye una mayor ventaja al momento de postular a un puesto laboral, Adelaida responde que en realidad todo depende de la persona y que si quiere algo y se lo propone, lo consigue. Aquí se detecta una ideología de la igualdad de oportunidades. Justifica esto en su observación de que las personas trabajan en su chacra, hilan o realizan diversas actividades. En Lima, hay fábricas y empresas que favorecen al hispanohablante, pero entre los andinos tienen por igual oportunidades e incluso menciona la posibilidad que se ha visto que tienen sus propias empresas.

\subsection{Lucía Gutiérrez}

Lucía considera que no es difícil hablar quechua, lo califica como normal. Manifestó que el castellano sí se le hizo un poco difícil al inicio, pues no conoció a otro quechuahablante estando en Lima los primeros momentos, pero no le parece que tenga una dificultad mayor.

P: ¿Qué será más dificil? ¿Para un quechuahablante aprender castellano o para un hispanohablante aprender quechua?

$R$ : Bueno, el querer es poder, no?

Además, manifiesta una ideología de la igualdad de oportunidades al decir que el que quiere, puede aprender a hablar cualquier lengua.

Su uso del quechua es frecuente, pues manifiesta que cuando reconoce personas de Ayacucho, Andahuaylas o Puquio, conversa con ellas y llega a tener confianza

38 Lengua \& Sociedad. Revista de Lingüística Teórica y Aplicada 
fácilmente con las personas mayores. También habla quechua en el mercado y en cualquier circunstancia en que sea posible y destaca que no tiene vergüenza.

Lucía considera que el quechua sí tiene prestigio nacional decididamente, mientras que manifiesta que el aimara lo tiene, pero con la aclaración de que se limita a la región que habitan sus hablantes, que es identificado con Puno o Juliaca.

P: ¿Usted consideraría que el quechua tiene prestigio a nivel nacional?

R: Sí.

$P:$ ¿Y el aimara, para usted, tiene prestigio a nivel nacional?

R: Bueno, aimara, este con gente de allá, de, cómo se llama? De Puno, Juliaca, por el Lago Titicaca, ahí hablan, no?. Es interesante aprender también. Sería bueno, no? Pero de ahí tengo pocas amistades, entonces casi no he tocado ese tema. Pero sería bueno aprender, ah? Importante.

$P$ : Y, a nivel nacional ¿usted cree que tiene prestigio el aimara? La gente lo ve como algo:, como así, com...todos quisieran de repente aprender aimara o...

$R$ : Yo creo que son como costumbres, así, de cada lugar, usted sabe que tiene sus cosas, hasta con sus dejos. Se respeta y se, cómo se lama? La verdad que valoro las personas que a veces se mantienen su idioma ahí, no? Hay muchos veo, inclusive mis paisanos, así, vergüenza, dice que ay nos va a decir que somos cholos, que somos serranos, pero no! Para nada, es algo bonito es una idioma. Por qué?, no? Por ejemplo, lo que me dices, no? Cómo se llama? El aimara, también si uno se propone, yo creo que sí. Inclusive yo, mi padre es de Juliaca, yo pienso aprender este a hablar aimara, porque de ahí hablan aimara, pues. Sí, algún día yo voy a hablar correctamente aimara.

Además, señala que ella sí tiene mucho interés en aprender la lengua aimara, debido a que su padre era de Juliaca y tiene aún en mente aprender dicha lengua.

P: Si le propusieran ir a un lugar de vacaciones donde se hable solamente aimara, no sé, un lugar de Juliaca, Puno, ¿usted estaría de acuerdo?

$R$ : Sí, también, porque aprendería su aimara. Así cuando vine a Lima no hablaba yo este: castellano, aprendí forzosamente. Aprendí sí o sí y sería bonito, no? Aprendería, y eso va a suceder conmigo porque pienso viajar a Juliaca.

Por otra parte, Lucía considera implícitamente que existe una igualdad de oportunidades, pues menciona casos favorables y no los casos desfavorables en 
Actitudes lingüísticas de los nativos hablantes de quechua hacia los hablantes de aimara Adán Ochoa Yupanqui

los que hablar quechua o aimara implican un perjuicio o quitan probabilidad de obtener un puesto de trabajo.

$P: ¿$ ¿Usted considera que quién tiene mejores oportunidades laborales, una persona que habla castellano, una que habla quechua o una que habla aimara?

$R$ : Bueno, yo veo a algunas personas que se puede decir que muy educados, hablan varios idiomas y se entienden mejor, no? Tienen ah, por ejemplo, en mi casa pa' arriba hay un doctor y habla él varios idiomas, no? Él no se avergüenza ni por uno ni por otro y yo creo que hablar más idiomas, guau, sería como sacarse pecho, ah? Y es bueno aprender, por qué no?

Resalta el hecho de que diga que ve a algunas personas y su desarrollo discursivo está centrado en personas que cumplen con características similares.

\subsection{Luis Ytusaca}

Luis Ytusaca es Proveniente de Puno y llegó a Lima a los 14 años aproximadamente. Considera que hablar quechua no es difícil y el castellano lo tuvo que aprender en el colegio.

Mencionó, además, que no conoce el aimara, pero intuye que su dificultad es similar a la del quechua.

Cuando se le preguntó si le gustaba hablar en quechua, respondió que sí, de una manera que acepta algo más que decididamente y justifica ese gusto en una convención cultural más que en un deseo individual.

R: Sí ((en tono de aceptación)) [me gusta hablar en quechua].

P: Por qué?

$R$ : Porque es nuestro idioma universal del Perú.

Cuando se le preguntó si utiliza el quechua con frecuencia, respondió que sí se encuentra con personas que hablan quechua y les habla en dicha lengua, aunque a veces le entienden pero no le responden.

Por otra parte, cuando se le preguntó si el quechua tiene prestigio a nivel nacional, su respuesta no fue muy optimista. Respecto al componente cognitivo de sus actitudes respecto al quechua se ve matizado negativamente.

\section{$R$ : Bueno, creo que [el quechua] no es tanto valorado, porque más se habla el castellano.}


El aimara corre una suerte similar, desde la perspectiva de Luis.

$R$ : Bueno, parece que está en un... no hay mucho apoyo, creo. Si hubiera apoyo este país a esos idiomas, todo el Perú hablaría también quechua o aimara.

Respecto a las posibilidades laborales, contestó que es más fácil contratar a un hispanohablante que a cualquier hablante de lenguas andinas.

R: Si la empresa no habla ese idioma, no puede contratarlo, pues, porque no entenderían, porque es más es el castellano. O ahora ya son idiomas este el inglés, hay otros idiomas.

\subsection{Victoria Altamirano}

Desde la percepción de Victoria Altamirano, el castellano es más difícil de hablar, porque cuando llegó a Lima no conocía a nadie que le pudiera interpretar o ayudar en su comunicación y su edad tampoco le ayudaba a adquirir un castellano fluido rápidamente.

Además, manifestó decididamente no tener interés en aprender aimara, como se observa en el siguiente extracto.

$P:$ A usted le gustaría aprender aimara?

R: No.

$P$ : No le gustaría (risas).

$R$ : Ya estoy viejita, ya, pe

P: Claro, claro, entiendo.

R: De joven, sí.

$P$ : (Risas) O sea sí le gustaría, nomás que es más difícil [...]

R: No.

Parece entrar en contradicción, pero rápidamente se reafirma en su hipotética elección de no aprender a hablar aimara.

\subsection{Justina Quispetupa}

Justina Quispetupa llegó a Lima a los nueve años de edad. La dificultad en el quechua es baja desde su percepción y el castellano le pareció difícil solo al inicio, cuando empezó a aprenderlo.

Respecto a la dificultad que percibe en el aimara, Justina respondió de la forma mostrada abajo. 
Actitudes lingüísticas de los nativos hablantes de quechua hacia los hablantes de aimara Adán Ochoa Yupanqui

R: Bueno, para mí sí porque es otra consonancia tiene pues, otro otro otro:: Parece más difícil que el quechua.

Por lo que sí le parece difícil, aunque no es posible determinar si esto le implica una valoración positiva o negativa.

En cuanto al prestigio del quechua, Justina respondió claramente que sí lo tiene, debido a las condiciones económicas que lo promueven directa o indirectamente.

R: Allá sí están dando bastante este importancia porque por el mismo turismo, la atracción, por la ruinas y por reivindicar el incanato, las costumbres, se está dando mucha importancia al quechua.

Esto indica que tiene una valoración positiva en el componente cognitivo hacia el quechua. No así con el aimara, como se observa más abajo.

Además, afirmó que le gusta hablar en quechua y aprovecha las oportunidades que hay en Lima para hablar en quechua con otras personas de su misma comunidad lingüística. Esto indica que tiene una valoración positiva también en el componente afectivo, aunque el ejemplo que mencionó se enmarcó en el contexto de su congregación religiosa, como se evidencia en el extracto a continuación.

R: Bueno, ahora en mi congregación, soy testigo de Jehová, ahí se está ehh se ha traducido toda la biblia a quechua y también damos testimonio en quechua. Hay una escuela en quechua y van para los pueblos alejados para poder este evangelizar, entonces, todo la información es quechua para las personas que son de las alturas, para las personas que no saben hablar castellano se les da el testimonio en quechua.

Por otro lado, señala que el prestigio del aimara sí es alto, pero acotado en la región en que habitan con mayor densidad sus usuarios, debido a su utilidad, por lo que constituye parte del componente cognitivo de su valoración hacia el aimara, el cual es positivo a nivel local.

R: Bueno, [el aimara] sí tiene prestigio para mí, porque::: para la zona donde está en Bolivia, porque como estamos limit, limitamos con Bolivia y Puno, tonces sí hay este:: es importante saber los dos idiomas, el quechua y el aimara, porque algunas palabras se entienden mitad quechua y mitad aimara, pero el sonido es muy diferente. 
No obstante, cuando se le preguntó su percepción respecto al prestigio a nivel nacional, la respuesta fue distinta.

R: [En Lima] el aimara no tanto, más están dando énfasis al quechua, porque es el idioma del incanato, pue, no? Pero el quechua es el que yo ahorita como he viajado a Cusco todo? El quechua es lo más importante por, el aimara no tanto en esto de la importancia.

Por lo tanto, a nivel nacional, el componente cognitivo de las actitudes hacia el aimara no es positivo.

Además, manifestó un ligero interés en aprender aimara, aunque no por razones especiales.

$P:$ ¿A usted le gustaría aprender aimara?

$R$ : Bueno, sí, porque es un idioma más.

Esto indica que valora a la lengua, en el sentido de que la reconoce, aunque le da una importancia igual que cualquier otra lengua, no superior ni inferior.

Respecto a la organización de actividades tradicionales, Justina explica que lo ideal es que un quechuahablante organice dichas actividades. Si la persona sabe aimara y castellano no es óptimo, pero si sabe quechua y aimara, sí se acepta.

P: Si tuviera que hacer alguna actividad tradicional de Cusco, ¿a usted le gustaría que una persona quechuahablante sea la que organice?

R: Bueno, sí, acá hay este las en, las fiestas que se hacen acá en Lima, de San Jerónimo, son las fiestas patronales. Ahí se habla en quechua y en castellano, claro dándole énfasis en quechua porque es un pueblo que es quechuahablante neto, no? Entonces ellos muchas veces enfatizan en quechua algunos mensajes, no? Que hablan con todos los paisanos. Sí, sí se hacen las fiestas costumbristas.

$P$ : O sea, sí se suele suelen organizarlo personas que hablan castellano y también quechua.

R: Sí, sí, las dos.

P: Y si hubiera alguien que habla aimara y quechua y podría también, sería igual de eficiente que lo organice?

R: No creo, pero los puneños están este::: pegando mucho a las fiestas patronales de San Jerónimo, mira. Y acá en Lima también han habido personas que han recibido los cargos, las fiestas patronales, no? 
Actitudes lingüísticas de los nativos hablantes de quechua hacia los hablantes de aimara Adán Ochoa Yupanqui

P: Aimaras o...

R: Aimaras, sí. O sea que tienen fe ahí al santo de ahí de San Jerónimo.

$P: Y$ cuándo salían mejor las actividades.

$R:$ El tres de setiembre de::

P: Ah ya, me refiero a cuándo (o.5) cuando lo organizaba un aimarahablante, un hablante de aimara o cuando lo organizaba un hablante del quechua. Cuándo salía mejor?

R: Bueno, el que habla el quechua porque no entienden el aimara los paisanos, porque tendrían que ser todos puneños para saber, comprender el aimara.

P: Ajá, pero y, digamos que sea un aimarahablante que también habla quechua, alguien que habla aimara y también quechua.

R: Bueno, si es que habla el quechua, sí le entienden, pues. Sí.

En cuanto a las oportunidades laborales, queda claro para Justina que el hablante de castellano tiene las mayores posibilidades de obtener una vacante laboral, le sigue el quechuahablante, dado que en ciertos casos se requiere, como el ejemplo que menciona respecto a la salud con la intención de señalar que no ocurre lo mismo con el aimara.

$P:$ ¿Quién tendría mejores oportunidades laborales?

R: Obviamente el que está hablando el castellano porque son pocos los que hablan el quechua. Recién se está dando la importancia a ese idioma, no? El que más oportunidades tiene es el que habla castellano.

P: Y quién tendría peores oportunidades laborales, ¿el que habla quechua o aimara?

$R$ : Bueno, dentro del Perú, el que habla el aimara no tendría mucha aceptación porque, mire, los médicos forzosamente ellos tienen que aprender el quechua así, trabajando en el Perú. Y van a provincia. Incluso acá mismo [...] yo le tengo que traducir qué dolencias tiene y qué padece, entonces en aimara no.

\section{Conclusiones}

Se observa que, en el componente cognoscitivo, los quechua hablantes, en general, tienen actitudes tendientes a ser negativas hacia el aimara, dado que todos reconocen que el castellano tiene más prestigio a nivel nacional, seguido por el quechua y en último lugar se encuentra el aimara. Asimismo, todos, a excepción de Luis Ytusaca (Quechua Cuzco-Collao), quien tiene un diagnóstico menos optimista,

$44 \quad$ Lengua \& Sociedad. Revista de Lingüística Teórica y Aplicada 
reconocen que el quechua ha sido revalorado en las últimas décadas, a diferencia de tiempos anteriores. Además, todos coinciden en que siempre tiene mayores oportunidades laborales un hispanohablante, seguido por un quechua hablante y, finalmente, el hablante de aimara es quien tiene peores oportunidades laborales.

Por otra parte, todos muestran, en mayor o menor medida, agrado por hablar el quechua, por lo que el componente afectivo de las actitudes lingüísticas hacia su propia lengua es alto, no así con el aimara, al cual se le da una valoración en el sentido de que se acepta su existencia, pero las actitudes son variadas. En este aspecto es clave la pregunta acerca de si les gustaría aprender a hablar aimara, dado que es análoga a la pregunta sobre qué tanto les gusta hablar su propia lengua (quechua). Entre los hablantes de Quechua Cuzco-Collao, Luis Ytusaca no muestra grandes deseos de aprender la lengua aimara, seguido por Justina Quispetupa, quien aprendería aimara únicamente porque es una lengua más y aprender siempre es bueno. Lucía Gutierrez sí muestra su intención decidida a aprender aimara y lo tiene muy justificado, de la misma manera, Adelaida Quispe también muestra deseos por aprender dicha lengua, por lo que el componente afectivo tiende a ser positivo en general, pero más desde los hablantes del Quechua Ayacucho.

Siguiendo con el componente afectivo, se da preferencia para la organización de actividades comunales a hispanohablantes en mayor medida, solo Justina Quispetupa (Quechua Cuzco-Collao) presenta la posibilidad de preferir a un quechua hablante y la preferencia por aimara hablantes para la organización de este tipo de actividades es igual y menor, dependiendo del colaborador y de algunas acotaciones que lo hagan elegible, pero todos tienen la misma tendencia en cuanto a esta preferencia.

La pregunta final que plantea la posibilidad de pasar vacaciones en un lugar donde se hable una determinada lengua, también da pistas acerca de las actitudes lingüísticas en el componente afectivo y la gran mayoría ha manifestado que habría dificultades para comunicarse de darse unas vacaciones así. La excepción se encuentra en Lucía Gutiérrez (Quechua Ayacucho), quien mostró una gran disposición hasta el punto de afirmar que sería conveniente porque así aprendería a hablar aimara, lo cual es un deseo suyo.

Finalmente, se concluye que el presente estudio de actitudes frente al aimara por los quechua hablantes es exploratorio y pionero por lo cual sus resultados son provisionales y mejorables dado que futuras indagaciones pueden proponerse profundizar y realizar comparaciones entre las actitudes que se tienen hacia el aimara según el tipo de quechua que se hable o según la procedencia geográfica, 
Actitudes lingüísticas de los nativos hablantes de quechua hacia los hablantes de aimara Adán Ochoa Yupanqui

y también se pueden plantear técnicas cuantitativas en la recolección de datos con muestras de mayor tamaño.

\section{Referencias bibliográficas}

Falcón, P. \& Mamani, L. (2017). Actitudes lingüísticas en contextos interculturales: Población asháninka Bajo Chirani. Revista de Lingüística Teórica y Aplicada, 55(1), 95-115.

Jimenez, P. (2017). Actitudes lingüisticas en la comunidad nativa Cubantia (Tesis de licenciatura). Universidad Nacional Mayor de San Marcos, Lima.

Cerrón-Palomino, R. (1987). Lingüística Quechua. Cusco: Centro Bartolomé de Las Casas.

Cuba, C. (2018). Tradición linguocultural y actitudes lingüisticas hacia las lenguas andinas (Tesis de doctorado). Universidad Nacional de San Agustín, Arequipa.

Hentschel, J. (2016). «En mí ya termina el quechua». Aproximaciones al uso lingüístico de hablantes bilingües (quechua-castellano) en el área urbana de Cochabamba, Bolivia. Indiana, 33(1). Ibero-Amerikanisches Institut Preußischer Kulturbesitz. Recuperado de http://www.redalyc.org/jatsRepo/2470/247046764006/html/index.html

Kierig, P. (2016). Actitudes hacia el aprendizaje de la lengua aymara en estudiantes de tercero de secundaria. Colegios fiscales y particulares de la zona sur y de la zona central de la ciudad de La Paz (Tesis de licenciatura). Universidad Mayor de San Andrés, La Paz.

Merma, G. (2007). Contacto lingüistico entre el español y el quechua: un enfoque cognitivo-pragmático de las transferencias morfosintácicas en el español andino peruano (Tesis doctoral). Universidad de Alicante, España. Disponible en https:// rua.ua.es/dspace/bitstream/10045/4114/1/tesis_doctoral_gladys_merma.pdf

Base de Datos de Pueblos Originarios. (02 de Diciembre de 2019). Quechua [Ficha]. Recuperado de https://bdpi.cultura.gob.pe/lenguas/quechua

Sihua, L. (2015). Language Attitudes and Identities in Multilingual China. Londres: Universidad Sun Yat-sen.

Vizcarra, F. (2012). Actitudes lingüisticas hacia las lenguas andinas por los estudiantes de la Facultad de Ciencias Sociales de la U.N.A. Puno (Tesis de maestría). Universidad Nacional del Altiplano, Puno. 


\section{ANEXO \\ ENTREVISTA SEMIDIRIGIDA}

OBJETIVO: Recoger información cualitativa detallada respecto de las actitudes lingüísticas de los quechuahablantes hacia los hispanohablantes y aimarahablantes.

Responda brevemente a las siguientes preguntas:

1. ¿Cuál es su nombre completo y edad?

2. ¿Dónde nació? ¿A qué edad vino a Lima?

3. ¿Sabe hablar alguna otra lengua aparte del quechua y el castellano?

4. ¿Es difícil hablar quechua? ¿Por qué? ¿El castellano? ¿Por qué?

5. ¿Debe ser difícil hablar aimara? ¿Por qué?

6. ¿Le gusta hablar en quechua? ¿Por qué?

7. ¿Cuando va al mercado o lugares que frecuenta y encuentra personas que también hablan quechua, usted les habla también en quechua? ¿Por qué?

8. ¿El quechua tiene prestigio a nivel nacional? ¿Por qué?

9. ¿El aimara tiene prestigio a nivel nacional? ¿Por qué?

10. ¿El castellano tiene prestigio a nivel nacional? ¿Por qué?

11. ¿Cuál de las tres tiene más prestigio? ¿Por qué?

12. ¿Cuál de las tres tiene menos prestigio? ¿Por qué?

13. ¿Te gustaría que una persona que habla aimara te enseñara a hablar su lengua? ¿Por qué?

14. ¿Con qué persona estarías de acuerdo para que organice las actividades de tu barrio: de una persona que habla quechua o una que habla aimara? ¿Por qué?

15. ¿Te gustaría pasar tus vacaciones en un sitio donde se hable quechua? ¿Por qué?

16. ¿Te gustaría pasar tus vacaciones en un sitio donde se hable castellano? ¿Por qué?

17. ¿Te gustaría pasar tus vacaciones en un sitio donde se hable aimara? ¿Por qué?

18. ¿Quién tiene más o mejores oportunidades laborales, una persona que habla castellano, una que habla quechua o una que habla aimara? ¿Por qué?

19. ¿Quién tiene menos o peores oportunidades laborales, una persona que habla castellano, una que habla quechua o una que habla aimara? ¿Por qué? 